\title{
Simple lignocaine regimen for transit to hospital after myocardial infarction
}

\author{
J. M. BARBER, D. MCC. BOYLE, Z. HUSSAIN, J. G. KELLY, AND \\ D. G. MCDEVITT \\ From the Cardiac Department, The Ulster Hospital, Dundonald, Belfast, and The Department of \\ Therapeutics and Pharmacology, The Queen's University of Belfast
}

\begin{abstract}
A simple combined intravenous/intramuscular regimen is described for lignocaine administration in the early vulnerable stage of myocardial infarction. Plasma levels in the therapeutic range are attained. This allows adequate drug protection during transport to hospital when an intravenous regimen may be impractical or impossible.
\end{abstract}

Lignocaine remains the first line of attack against ventricular arrhythmia after myocardial infarction. Plasma levels required for this purpose are said to lie between 6.4 and $21 \mu \mathrm{mol} / 1(1.5$ to $5 \mu \mathrm{g} / \mathrm{ml})$ (Harrison and Alderman, 1971; Collinsworth et al., 1974; Koch-Weser, 1975; Aps et al., 1976). There is difficulty in maintaining adequate plasma concentrations in the first two hours of treatment using conventional intravenous dosage (Aps et al., 1976). If such treatment is started in the patient's home, he is likely to be denied protection from arrhythmias at a time when the risk is greatest and surveillance most difficult.

We report our experience using a simple combination of an intravenous bolus and intramuscular injection as a means of overcoming these difficulties.

\section{Methods}

Twelve consecutive patients admitted to the Coronary Care Unit, who fulfilled our criteria for lignocaine therapy (Walsh et al., 1972) and who had not received any antiarrhythmic drug outside hospital, received the combined intravenous/intramuscular regimen. Two patients were excluded subsequently because of technical problems relating to the timing of samples for estimation of drug concentration. Of the remaining 10,8 were men and 2 women, and their ages varied from 28 to 74 years. One patient (case 9) had mitral stenosis and was in heart failure. All the remainder had had a myocardial infarct and one of these (case 8) also had pulmonary venous congestion. Their weights varied from 55.3 to $76.7 \mathrm{~kg}$. The electrocardiograms of these patients were recorded continuously by a Received for publication 19 May 1977 direct-writing electrocardiograph over a 4-hour period and blood pressure was recorded at 15minute intervals. The recordings were scanned by two observers for changes in heart rate or rhythm.

The patients were given $100 \mathrm{mg}$ lignocaine hydrochloride by intravenous injection over 2 minutes into an arm vein. Five minutes after the beginning of the intravenous injection, $300 \mathrm{mg}$ were given by intramuscular injection into the deltoid muscle. The time of the intramuscular injection was taken as zero time and $10 \mathrm{ml}$ blood samples were taken from a vein in the other arm 2 minutes before zero time and then at $3,5,10,15,30,45,60,90,120,150,180$, and 240 minutes. The blood was centrifuged and stored at $4^{\circ} \mathrm{C}$ until plasma concentrations were estimated.

Plasma lignocaine was estimated by a gas chromatographic method. One $\mathrm{ml}$ samples of plasma, containing diphenhydramine $5 \mu \mathrm{g}$ as an internal standard, were made alkaline with $0.5 \mathrm{ml}$ of $2 \mathrm{M}$ $\mathrm{NaOH}$. Samples were extracted with $5 \mathrm{ml}$ portions of ether. The ether layer was removed and evaporated to dryness. Samples were reconstituted with $30 \mu \mathrm{l}$ portions of dichloromethane and $1 \mu \mathrm{l}$ portions injected into a gas chromatograph (PerkinElmer model F11) fitted with a flame-ionisation detector. The column was glass, $6 \mathrm{ft}$ in length and 0.25 in outer diameter and was packed with 2 per cent carbowax $20 \mathrm{M}$ on $\mathrm{KOH}$ treated chromosorb G. Oven temperature was $200^{\circ} \mathrm{C}$ and nitrogen carrier gas flow rate was $40 \mathrm{ml} / \mathrm{min}$. The relative retention time of lignocaine to diphenhydramine was $1 \cdot 4$.

Drug half-life ( $\left.t \frac{1}{2}\right)$ was estimated from the terminal portion of the plasma curves by least squares regression analysis. The data from 60 to 240 minutes 
was used ( 45 to 240 minutes for case 8 ). The area under the plasma concentration/time curve was estimated using the trapezoidal rule, and drug clearance (dose/area) calculated, assuming that all the drug from the intramuscular injection site had been absorbed and therefore that the total systemic dose was $400 \mathrm{mg}$. The volume of distribution (Vd) was derived from the equation:

$$
\text { Clearance }=\text { Vd. } \beta \text {, where } \beta=\frac{0.693}{t^{\frac{1}{2}}} \text {. }
$$

\section{Results}

No patient developed symptomatic or haemodynamic side effects during the 4-hour period of observation. One patient (case 3) required further lignocaine for recurrent arrhythmia soon after the 4-hour period was over.

The Table and Figure summarise plasma lignocaine concentrations found in the patients. In only one patient did the plasma level fall below $6.4 \mu \mathrm{mol} / 1$ $(1.5 \mu \mathrm{g} / \mathrm{ml})$ in the first 2 hours. At 4 hours, only 4 patients had plasma levels above $6.4 \mu \mathrm{mol} / 1$ $(1.5 \mu \mathrm{g} / \mathrm{ml})$.

The mean drug half-life was $136.2 \pm 29.3$ minutes with a mean lignocaine clearance of $507 \mathrm{ml} / \mathrm{min}$ and volume of distribution of 82 litres. The range of values are shown in the Table.

\section{Discussion}

In myocardial infarction the commonest cause of death is ventricular arrhythmia occurring in the early phase of the attack (Pantridge and Geddes, 1967). The generally accepted first line drug to counter this is lignocaine and there is some clinical evidence that its early use may lower mortality (Morgensen, 1970; Valentine et al., 1974).

The usual lignocaine regimen is an intravenous

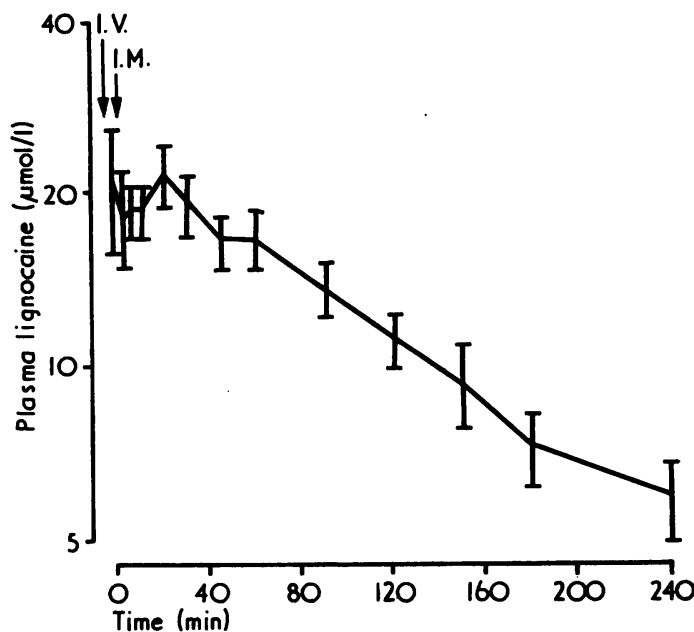

Fig. Mean plasma lignocaine concentrations after the administration of lignocaine $100 \mathrm{mg}$ intravenously at -3 minutes and $300 \mathrm{mg}$ intramuscularly at time 0 . Results are mean of 10 patients $\pm S E M$.

bolus of 1 to $2 \mathrm{mg} / \mathrm{kg}$, followed by constant infusion of 1 to $4 \mathrm{mg} / \mathrm{min}$. Aps et al. (1976) have emphasised that this is associated with a period of about 2 hours when the plasma concentration is subtherapeutic and have recommended a more complex regimen involving different and reducing rates of infusion. We have found that meticulous control of intravenous infusion flow rates is very difficult during travel in an ambulance and an alternative seemed desirable. The combination of an intravenous bolus and intramuscular injection was a possible answer, and we were pleased to find that in all our patients therapeutic levels were maintained long enough to allow transport from home to hospital. The mean plasma concentrations in the first two hours of treatment were similar to those re-

Table Plasma lignocaine concentrations and pharmacokinetic measurements after intravenous/intramuscular lignocaine

\begin{tabular}{|c|c|c|c|c|c|c|c|c|c|c|c|c|c|c|c|c|c|}
\hline & \multicolumn{13}{|c|}{ Plasma lignocaine concentration ( $\mu \mathrm{mol} / \mathrm{l}$ ) } & \multirow{2}{*}{$\begin{array}{l}\frac{t}{2} \\
-(\min )\end{array}$} & \multirow{2}{*}{$\begin{array}{l}\beta \\
\left(\min ^{-1}\right)\end{array}$} & \multirow{2}{*}{$\begin{array}{l}\text { Clearance } \\
(\mathrm{ml} / \mathrm{min})\end{array}$} & \multirow{2}{*}{$\begin{array}{l}V d \\
(l)\end{array}$} \\
\hline & $\begin{array}{l}-2 \\
\text { (min) }\end{array}$ & 3 & 5 & 10 & 20 & 30 & 45 & 60 & 90 & 120 & 150 & 180 & $\begin{array}{l}240 \\
(\text { min })\end{array}$ & & & & \\
\hline $\begin{array}{c}1 \\
2 \\
3 \\
4 \\
5 \\
6 \\
7 \\
8 \\
9 \\
10 \\
\text { Mean } \\
\text { SEM }\end{array}$ & $\begin{array}{r}29 \cdot 0 \\
11 \cdot 5 \\
25 \cdot 2 \\
46 \cdot 5 \\
29 \cdot 0 \\
19 \cdot 2 \\
5 \cdot 5 \\
47 \cdot 8 \\
4 \cdot 3 \\
2 \cdot 1 \\
22 \cdot 0 \\
5 \cdot 2\end{array}$ & $\begin{array}{l}17.5 \\
16.6 \\
- \\
13 \cdot 2 \\
42 \cdot 7 \\
16.6 \\
12 \cdot 8 \\
18 \cdot 8 \\
9.8 \\
18.5 \\
3.6\end{array}$ & $\begin{array}{l}18 \cdot 8 \\
10 \cdot 2 \\
26.5 \\
19 \cdot 2 \\
18.3 \\
13.7 \\
21 \cdot 8 \\
25 \cdot 6 \\
13.7 \\
18.6 \\
1.8\end{array}$ & $\begin{array}{l}22.2 \\
17.9 \\
23.9 \\
\overline{15.8} \\
\overline{13.2} \\
25 \cdot 3 \\
18.8 \\
12.8 \\
18.7 \\
1.7\end{array}$ & $\begin{array}{r}17 \cdot 9 \\
20 \cdot 1 \\
22 \cdot 6 \\
25 \cdot 6 \\
19 \cdot 2 \\
40 \cdot 5 \\
24 \cdot 3 \\
20 \cdot 1 \\
15 \cdot 4 \\
13 \cdot 2 \\
21 \cdot 9 \\
2 \cdot 4\end{array}$ & $\begin{array}{r}22 \cdot 6 \\
18 \cdot 3 \\
16 \cdot 2 \\
16 \cdot 6 \\
14 \cdot 9 \\
32 \cdot 9 \\
23 \cdot 0 \\
24 \cdot 7 \\
11 \cdot 1 \\
11 \cdot 5 \\
19 \cdot 2 \\
2 \cdot 1\end{array}$ & $\begin{array}{r}17 \cdot 5 \\
15 \cdot 8 \\
12 \cdot 8 \\
23 \cdot 0 \\
12 \cdot 8 \\
27 \cdot 3 \\
17 \cdot 9 \\
11 \cdot 9 \\
12 \cdot 8 \\
13 \cdot 2 \\
16 \cdot 5 \\
1.6\end{array}$ & $\begin{array}{r}21.8 \\
17.9 \\
16.6 \\
22.2 \\
11.9 \\
23.0 \\
18.8 \\
-7.7 \\
11.5 \\
16.8 \\
1.8\end{array}$ & $\begin{array}{r}18 \cdot 3 \\
19 \cdot 2 \\
11 \cdot 9 \\
13 \cdot 7 \\
15 \cdot 8 \\
17 \cdot 1 \\
15 \cdot 8 \\
0.8 \\
6 \cdot 0 \\
9 \cdot 4 \\
13.7 \\
1.4\end{array}$ & $\begin{array}{r}15 \cdot 8 \\
11.9 \\
9.4 \\
- \\
14.1 \\
14.5 \\
11.9 \\
7.3 \\
5.1 \\
9.0 \\
11.0 \\
1.2\end{array}$ & $\begin{array}{r}16 \cdot 2 \\
7 \cdot 3 \\
6 \cdot 8 \\
10 \cdot 2 \\
11 \cdot 9 \\
16 \cdot 6 \\
5 \cdot 5 \\
5 \cdot 5 \\
3 \cdot 0 \\
9 \cdot 8 \\
9 \cdot 3 \\
1 \cdot 4\end{array}$ & $\begin{array}{r}10 \cdot 7 \\
4.3 \\
5.5 \\
6.4 \\
11 \cdot 9 \\
10.7 \\
5.1 \\
5.1 \\
2.6 \\
8.5 \\
7 \cdot 1 \\
1.0\end{array}$ & $\begin{array}{r}6 \cdot 8 \\
4 \cdot 3 \\
3 \cdot 8 \\
5 \cdot 1 \\
8 \cdot 5 \\
10 \cdot 7 \\
4 \cdot 3 \\
2 \cdot 1 \\
7 \cdot 7 \\
5 \cdot 9 \\
0.9\end{array}$ & $\begin{array}{r}114 \cdot 5 \\
71 \cdot 7 \\
86 \cdot 0 \\
88 \cdot 5 \\
177 \cdot 1 \\
177 \cdot 1 \\
75 \cdot 3 \\
103 \cdot 8 \\
91 \cdot 2 \\
376 \cdot 3 \\
136 \cdot 2 \\
29 \cdot 3\end{array}$ & $\begin{array}{l}0.0062 \\
0.0096 \\
0.008 \\
0.0078 \\
0.0039 \\
0.0039 \\
0.0092 \\
0.0066 \\
0.0075 \\
0.0018 \\
0.0064 \\
0.0008\end{array}$ & $\begin{array}{r}669 \\
540 \\
553 \\
440 \\
511 \\
334 \\
537 \\
591 \\
733 \\
257 \\
507 \\
51\end{array}$ & $\begin{array}{r}108 \\
56 \\
69 \\
56 \\
80 \\
60 \\
58 \\
90 \\
98 \\
142 \\
82 \\
9\end{array}$ \\
\hline
\end{tabular}

Conversion: SI to traditional units-lignocaine: $1 \mu \mathrm{mol} / 1 \simeq 0.23 \mu \mathrm{g} / \mathrm{ml}$. 
ported by Aps et al. (1976) using his more complicated regimen. Most lethal arrhythmias occur in the first few hours after the onset of myocardial infarction, so that in many patients no further antiarrhythmic drug may be needed after receiving the combined intravenous/intramuscular lignocaine. However, the main practical advantage of the combination is that it ensures adequate plasma concentration in the early vulnerable phase while the patient is being transported to hospital, whether by specially equipped ambulance or not.

We cannot say if the doses we have used would be appropriate in patients with severe shock or heart failure who may handle the drug differently, but these complications rarely occur during the very early phase of the attack. Certainly, the estimates of half-life, clearance, and volume of distribution of lignocaine obtained in this present study appear to lie somewhere between those previously found after constant intravenous infusion in normal volunteers (Boyes et al., 1971) and in patients after myocardial infarction (Prescott and Nimmo, 1971).

We thank the nursing and medical staff and medical students at the Coronary Care Unit, Ulster Hospital.

\section{References}

Aps, C., Bell, J. A., Jenkins, B. S., Poole-Wilson, P. A., and Reynolds, F. (1976). Logical approach to lignocaine therapy. British Medical fournal, 1, 13-15.
Boyes, R. N., Scott, D. B., Jebson, P. J., Godman, M. J., and Julian, D. G. (1971). Pharmacokinetics of lidocaine in man. Clinical Pharmacology and Therapeutics, 12, 105-116.

Collinsworth, K. A., Kalman, S. M., and Harrison, D. C. (1974). The clinical pharmacology of lidocaine as an antiarrhythmic drug. Circulation, 59, 1217-1230.

Harrison, D. C., and Alderman, E. L. (1971). Relation of blood levels to clinical effectiveness of lidocaine. In Lidocaine in the Treatment of Ventricular Arrhythmias, p. 178. Ed. by D. B. Scott and D. G. Julian. Livingstone, Edinburgh and London.

Koch-Weser, J. (1975). Drug interactions in cardiovascular therapy. American Heart fournal, 90, 93-116.

Morgensen, L. (1970). Ventricular tachyarrhythmias and lignocaine prophylaxis in acute myocardial infarction. A clinical and therapeutic study. Acta Medica Scandinavica, Suppl. 513.

Pantridge, J. F., and Geddes, J. S. (1967). A mobile intensivecare unit in the management of myocardial infarction. Lancet, 2, 271-273.

Prescott, L. F., and Nimmo, J. (1971). Plasma lidocaine concentrations during and after prolonged infusions in patients with myocardial infarction. In Lidocaine in the Treatment of Ventricular Arrhythmias, p. 168. Ed. by D. B. Scott and D. G. Julian. Livingstone, Edinburgh and London.

Valentine, P. A., Frew, J. L., Mashford, M. L., and Sloman, J. G. (1974). Lidocaine in the prevention of sudden death in the pre-hospital phase of acute infarction. A double blind study. New England fournal of Medicine, 291, 1327-1331.

Walsh, M. J., Shivalingappa, G., Scaria, K., Morrison, C., Kumar, B., Farnan,C.,Chaturvedi, N. C., Boyle, D. McC., and Barber, J. M. (1972). Mobile coronary care. British Heart fournal, 34, 701-704.

Requests for reprints to Dr. D. McC. Boyle, The Ulster Hospital, Dundonald, Belfast BT16 0RH. 